\section{Discussion}

Three separate strands can be discerned in these developments. The first is a policy move by the government away from agreed guidelines for hospital provision to local arrangements. It would appear that in some areas at least this is resulting in poor provision for a very vulnerable group of people. Unfortunately they are not a vociferous group so that 'consumer pressure' is unlikely to be effective in improving their lot and there is a need for some central guidance to ensure adequate quantity and quality of provision.

The second strand is the move to a 'purchaserprovider' model of care with the health authority contracting provision out to the voluntary/private sectors. It is not clear what advantages might accrue from this were it not confounded by the third strand of shifting cost from the NHS to the social security budget. The need to make patients eligible for money from social security is presumably what dictated the situation where consultants no longer have responsibility for continuing care patients. Many consultants believe that a regular review by a psychiatrist can contribute to a better quality of care for patients and there is some indirect evidence of this from a study in the USA (Rovner et al, 1990).

When the community care part of the NHS Act is implemented, local social services authorities will be given a budget for future admissions of people to residential and nursing home care. Social security payments will no longer be available (except for those already in care) and it is not clear what will be the the status of some current schemes set up to exploit the availability of these payments. More importantly, the budget given to the local authorities will not be 'ringfenced' and may be used to augment community care (or even child care) rather than to support people in residential/nursing homes. Though there is a superficial attractiveness to improving community care at the expense of 'institutional' care, our rate of residential/nursing home care in this country is already low in comparison to the structure of our population.

In the absence of any definition of health authority guidelines for continuing care of old people with severe dementia, there will continue to be pressure on health authorities to save money by minimising facilities and pushing patients out to the voluntary/ private sectors. With its limited grant, the local social services authority will be under equal pressure to re-define people with dementia as a 'health' problem. Dementia sufferers could well be caught in the middle of these conflicting pressures and be quite literally 'left out in the cold'.

Constructive plans are needed to ensure adequate provision for this vulnerable group of people, to avoid attempts to 'pass the buck' for their care and to ensure that issues such as continuing consultant responsibility are decided on clinical grounds and not dictated by financial vagaries.

\section{Reference}

Rovner, B. W., Lucas-Blaustein, J., Folstein, M. F. \& SMITH, S. W. (1990) International Journal of Geriatric Psychiatry, 5, 233-238.

Helen Annis, Consultant Psychiatrist, Aldrington Day Hospital, Brighton; Brian R. Ballinger, Consultant Psychiatrist, Royal Dundee Liff Hospital; Olga Burma-Wilson, Consultant Psychiatrist for the Elderly, Huddersfield Health Authority; Rob Jones, Senior Lecturer in Psychiatry, Department of Health Care of the Elderly, Nottingham; and John P. Wattis, Senior Lecturer in Psychiatry for Old People, Department of Psychiatry, St James's University Hospital, Leeds

\title{
Patients, psychiatrists and the Community Charge
}

April 1990 (a year earlier in Scotland) saw the introduction in Great Britain of a new tax, the Community Charge, replacing the old rating system. The government's aim in introducing the Community Charge is to ensure that as many people as possible pay the Community Charge, so that a far greater number of local electors have an incentive to consider the costs as well as the benefits of extra spending. The tax continues a subject of controversy into which psychiatrists (and other doctors) are drawn in their professional role since among the limited categories of people exempted by the legislation from payment of the tax are those who are too ill to understand its nature, people who are indefinitely resident in hospital, and people who are detained by the state and so have no choice of residence. In addition, the poorest in the population are exempt from $80 \%$ of the payment, as are full-time students, and some people who previously paid rates are allowed limits on the increase in payments they make for a transitional period.

Advice has been issued to doctors by government on the exemption for the severely mentally impaired (Reed, 1990) but there continue to be uncertainties expressed by doctors. This note is intended to clarify the position. 
People who are detained under the Mental Health Act (or other legislation) are exempt from the Community Charge; this includes patients on leave and it may be helpful to patients and their families to advise them of this. Long stay residents whose sole or main residence is in a hospital or residential home are also exempt and there appears to be nothing in the legislation which would prevent anybody resident in hospital who is not expected to leave claiming exemption as a long stay patient. Some local authorities use a guideline of six months, after which a hospital patient is deemed to be solely or mainly resident in the hospital. Guidelines issued by the Department of the Environment suggest that authorities will wish to have regard to the housing benefit regulations which define a person as being resident in a hospital when they have been there for 52 weeks. This is a matter on which local Registration Officers can exercise discretion.

The exempt group which has caused most concern to psychiatrists is the group defined as suffering "severe mental impairment". The phrase "severe mental impairment" used here is defined in the Local Government Finance Act 1988 as amended by the Personal Community Charge (Exemption for the Severely Mentally Impaired) Order 1990. Anyone familiar with the Mental Health Act 1983 must be clear that the definition is quite different in the two Acts and put the Mental Health Act definition out of their minds for this purpose (unfortunately the legislature chose to use the same words for two different groups of people in different Acts of Parliament). In order to claim exemption from the Community Charge as being severely mentally impaired, two sorts of conditions need to be satisfied. Firstly, the patient must suffer from "severe mental impairment" as defined in the Local Government Finance Act 1988, as amended, and secondly, they must be entitled to (not necessarily in receipt of) one of certain specified benefits which are:

invalidity pension, severe disablement allowance, an unemployability supplement, an unemployability allowance, attendance allowance or constant attendance allowance.

The claim for exemption is started by an applicant, usually a relative or other carer of the severely mentally impaired person, making a claim to the local Community Charge Registration Officer. The claim form includes a statement about which of the relevant benefits is being drawn. If it is in order the Community Charge Registration Officer sends a form for completion to the doctor named on it, who is usually the person's general practitioner. The doctor is expected to certify that in his or her opinion the patient is (or is not) severely mentally impaired and is also expected to send back the form without completing it if he or she is unclear on the matter. The Community Charge Registration Officer can then invite the applicant to name another doctor to whom it may be sent. (The latter point is not stated on the form.)
"Severe mental impairment", which is defined as a severe impairment of intelligence and of social function which appears to be permanent, does not depend on the presence of any particular diagnosis. It can be certified when the patient suffers from a severely impaired level of intelligence and social functioning for whatever reason, whether this be, say, a severe dementing process or severely impaired ability to function mentally following a psychotic illness or severe mental handicap or following brain damage providing the condition is permanent.

There is no formal method of estimating the degree of impairment which is a matter of clinical judgement for the doctor concerned. It is suggested that a lack of understanding of the nature of the services provided by local government and their relationship to the tax being levied is what should be present (Metters, 1989). Rather curiously, there is no appeal mechanism. It has been agreed between the Government and the profession that no charge will be made for certificates given by doctors. No procedures have been laid down for confidentiality so the applicant becomes aware of the doctor's decision as to certification. In most cases, the applicant for exemption will be the patient's carer but it may sometimes be appropriate for a professional, for example, a social worker or community psychiatric nurse, to apply. There are reports of applications by non-family members being questioned by Community Charge Registration Officers but there is no rule laid down as to who may or who may not be an applicant.

Many patients with long term mental disorders live in an impoverished state and, while they may understand the nature of the Community Charge too well to qualify for exemption as severely mentally impaired, they may be entitled to a $80 \%$ rebate because of their financial situation. It may be unnecessarily intrusive for a doctor to enquire into the financial state of every patient, but there are likely to be patients and carers who do not understand the necessary rules and procedures well enough to initiate applications for themselves. Given that a rebate is likely to be of substantial benefit to their patients, members of the College should make sure they have informed themselves who locally can be recommended to provide the necessary information and help. This help may also be needed for relatives and carers of patients who could claim exemption for the patient as "severely mentally impaired" if he or she claimed a benefit they are entitled to.

Finally, there appear to be cases where families do not initiate claims for exemption as they prefer to pay for their sick relative rather than record formally the existence of mental illness in a family member. Fear of stigmatisation takes many forms!

National policy on the Community Charge has changed radically in the last few months (and may do so again). At the time of writing it seems probable that 
it will continue for at least two more financial years and the text above will remain relevant for that time.

\section{References}

MetTers, J. S. 'Exemption of People with Severe Mental Impairment from Liability to pay the Community Charge' PL/CO (89), 12 November 1989.
ReED, J. 'Dear Doctor' Letter PL/CO (90) 7, 2 July 1990.

This statement includes comments and corrections made by the Department of Health and the Department of the Environment.

Dr A. R. M. Freeman

April 1991

Public Policy Committee

\section{MRCPsych Examinations notice}

The Court of Electors recently issued guidelines on the way in which two topics should be examined in the MRCPsych Examinations. The statements, which are summarised below, will be welcomed as a way of clarifying the many complex issues surrounding these topics, and it is hoped that they will prove to be helpful both to Examiners and candidates alike.

\section{Classification of disorders (MRCPsych Part I, Part II and Membership Examinations)}

The Clinical and Oral Examinations

All candidates will be expected to demonstrate, where necessary, a working knowledge of the ICD. It is, however, important that candidates offering the DSM classification should not be penalised, providing their presentation does justice to the clinical problem under consideration.

\section{The Written Papers}

The same considerations will apply with regard to Essay questions. In the case of the Multiple Choice and Short Answer Question Papers, any questions on classification of disorders will be confined to the principles which underlie either the ICD or DSM.

\section{Law in the Membership and MRCPsych Part II Examinations}

The Clinical and Oral Examinations

It is important that candidates should be conversant with the principles of mental health law that apply in the British Isles and other common law countries. It is also important that they are familiar with the law of one country in the United Kingdom or the Republic of Ireland. Candidates should be asked to nominate the law with which they are familiar. Those training outside the UK and Republic of Ireland (i.e. Hong Kong, Canada, USA, Australia and New Zealand) should be expected to demonstrate knowledge of British or Irish law (whichever option they may choose) at an appropriate level.

This is a complex and difficult field which poses problems for both Examiners and candidates. Much will depend upon the good sense and judgement of Examiners with regard to what should be expected of candidates. Paramount in all this is recognition that questioning on specifics of law should be tailored very carefully to each candidate's selected option.

In addition, candidates and Examiners should not depend upon numerical reference to sections of the particular law which they are describing, but should place emphasis upon a brief description of their content, e.g. 'emergency admission', 'transfer from prison', 'compulsory admission', etc.

\section{The Written Papers}

The above principles will also apply with regard to questions on Law which may appear in the Short Answer Question and/or Essay Paper.

Professor H. G. MoRGaN Chief Examiner

\section{SPECIAL ANNIVERSARY MEETING SATURDAY 27 JULY 1991}

On 27 July 1841 the Association of Medical Officers of Hospitals for the Insane was founded at Horton Road Hospital in Gloucester; 130 years later this organisation matured into the Royal College of Psychiatrists.

On 27 July 1991 a special one day meeting is being hosted jointly by the South Western Division and the History of Psychiatry Special Interest Group at Wotton House in Horton Road to celebrate 150 years of British psychiatry.

Attendance is open to all College members who book beforehand. Places will be limited to 120 . The programme and further details are available from Dr Richard Williams, Honorary Secretary of the South Western Division at the College, 17 Belgrave Square, London SWIX 8PG. 